Cite this: RSC Advances, 2013, 3, 4086

Received 12th December 2012 Accepted 14th January 2013

DOI: $10.1039 / c 3 r a 23304 a$

www.rsc.org/advances

\title{
Tantalum-oxide catalysed chemical vapour deposition of single- and multi-walled carbon nanotubes $†$
}

\author{
Bernhard C. Bayer, ${ }^{\text {ta }}$ Carla Castellarin-Cudia, ${ }^{\text {bc }}$ Raoul Blume, ${ }^{\text {d Stephen A. Steiner III, }}$ \\ Caterina Ducati, ${ }^{f}$ Daping Chu, ${ }^{a}$ Andrea Goldoni, ${ }^{c}$ Axel Knop-Gericke, ${ }^{9}$

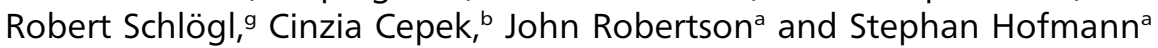

\begin{abstract}
Tantalum-oxide thin films are shown to catalyse single- and multi-walled carbon nanotube growth by chemical vapour deposition. A low film thickness, the nature of the support material (best results with $\mathrm{SiO}_{2}$ ) and an atmospheric process gas pressure are of key importance for successful nanotube nucleation. Strong material interactions, such as silicide formation, inhibit nanotube growth. In situ X-ray photoelectron spectroscopy indicates that no catalyst reduction to Ta-metal or Ta-carbide occurs during our nanotube growth conditions and that the catalytically active phase is the Ta-oxide phase. Such a reduction-free oxide catalyst can be technologically advantageous.
\end{abstract}

\section{Introduction}

Chemical vapour deposition (CVD) of carbon nanotubes (CNTs) involves the decomposition of gaseous carbon precursors over a nanoparticle catalyst and subsequent incorporation of the carbon into the growing nanotube structure. ${ }^{1}$ To date, the most extensively studied "standard" catalyst materials are metallic $\mathrm{Fe}$, Ni and $\mathrm{Co}^{2-4}$ However, recently a range of other catalyst materials has been shown to nucleate CNTs by CVD as well. These include "non-standard" metals, ${ }^{5-9}$ semiconductor nanoparticles, ${ }^{10,11}$ nanostructured carbon materials $^{12-14}$ and oxide nanoparticles. ${ }^{15-26}$ Likewise, first attempts at oxide-catalysed graphene CVD have recently been made. ${ }^{27,28}$

This gradually expanding plurality of catalyst materials for CNT CVD has challenged many previously accepted aspects of the CNT growth model ${ }^{2,29}$ such as the need for a transition metal catalyst, the need for a balanced finite carbon solubility in the catalyst ${ }^{30}$ and the need for a balance in the metalcarbon valence orbital overlap. ${ }^{9}$ Fundamentally, it remains unclear as to what extent various catalyst nanoparticles serve

\footnotetext{
${ }^{a}$ Department of Engineering, University of Cambridge, Cambridge, CB3 OFA, UK. E-mail: bcb25@cam.ac.uk; Fax: +44 (0)1223/748348; Tel: +44 (0)1223/748291 ${ }^{b}$ Istituto Officina dei Materiali-CNR, Laboratorio TASC, I-34149 Trieste, Italy ${ }^{c}$ Sincrotrone Trieste SCPA, I-34149 Trieste, Italy

${ }^{d}$ Helmholtz-Zentrum Berlin für Materialien und Energie, D-12489 Berlin, Germany ${ }^{e}$ Department of Aeronautics and Astronautics, Massachusetts Institute of Technology, Cambridge, MA 02139, USA

${ }^{f}$ Department of Materials Science and Metallurgy, University of Cambridge, Cambridge, CB2 3QZ, UK

${ }^{g}$ Fritz-Haber-Institut der Max-Planck-Gesellschaft, D-14195 Berlin-Dahlem, Germany $\dagger$ Electronic supplementary information (ESI) available. See DOI: 10.1039/ c3ra23304a
}

as chemical catalysts that lower reaction barriers and/or as geometrical seeding templates for nanotube cap formation. ${ }^{31}$

Oxide catalysts in particular are puzzling: Refractory metaloxides have been widely used as supports for standard metal catalysts in CNT growth but had previously generally been considered to be chemically inert towards nanotube formation. We however showed that hard-to-reduce $\mathrm{ZrO}_{2}$ nanoparticles facilitate nanotube growth without reduction of the zirconia at any stage during the CVD process. ${ }^{20}$ In situ X-ray photoelectron spectroscopy (XPS) suggested that chemically active, substoichiometric (surface) defects on the otherwise inert oxide promote CNT nucleation. ${ }^{20}$ Likewise, for the technologically important oxide catalyst $\mathrm{SiO}_{x}$ there is currently an intense debate whether the nanoparticles facilitating CNT growth remain as an oxide, ${ }^{21}$ form surface defects, ${ }^{22}$ reduce to $\mathrm{SiC}$ on the surface, ${ }^{24}$ reduce to SiC entirely in the bulk ${ }^{23}$ or are even liquid $^{19}$ during CVD.

Similar to $\mathrm{Si}$ and $\mathrm{Zr}$, tantalum (Ta) can form stable compounds with $\mathrm{C}, \mathrm{O}, \mathrm{H}$ or $\mathrm{N}$, respectively, ${ }^{32,33}$ which are all common elements in nanotube CVD process gases. In particular, Ta is (similar to Si) a slightly weaker oxide former than $\mathrm{Zr}$ but $\mathrm{Ta}$ is (similar to $\mathrm{Zr}$ ) a stronger carbide former than $\mathrm{Si}^{34}$ These properties suggest Ta-oxide as an interesting model system to further examine the growth mechanism(s) of CNTs from non-standard catalysts.

Ta-based catalysts have not been previously used to nucleate CNTs but Ta can promote graphitisation of carbon $^{35,36}$ and was reported as a catalyst for $\mathrm{BN}$ nanotube ${ }^{37}$ and $\mathrm{GaN}^{38}$ and $\mathrm{SnO}_{\mathrm{x}}{ }^{39}$ nanowire growth. However the state of the $\mathrm{Ta}$ in these reactions remains unclear. Ta-oxides ${ }^{40-42}$ and Tacarbides $^{43-45}$ are well known catalysts for various heterogeneous catalytic processes. Because of their compatibility with ultra-large-scale-integration (ULSI) manufacturing, metallic Ta 
thin films have been previously studied as an electrically conductive support material for CNT growth employing standard catalysts ${ }^{34,46}$ and Ta has been investigated as an admixture component in FeTa CNT co-catalysts. ${ }^{47}$ Ta and its oxides and carbides are non-ferromagnetic, ${ }^{48,49}$ making Tabased CNT catalysts appealing for magneto-electronic CNT devices. Ta-oxides $\left(\mathrm{Ta}_{2} \mathrm{O}_{5}\right)$ are also of high technological importance (e.g., high-k dielectrics and optical coatings) ${ }^{50}$

Here, we demonstrate that Ta-oxide catalyses the growth of single-walled nanotubes (SWNTs) and multi-walled nanotubes (MWNTs). MWNT growth from Ta-oxide thin films $(<1 \mathrm{~nm})$ on $\mathrm{SiO}_{2}$-covered wafers can be achieved at moderate temperatures as low as $\sim 650{ }^{\circ} \mathrm{C}$. This is in contrast to a large fraction of other "non-standard" CNT growth catalysts which can only nucleate SWNTs and work only at high temperatures above $900{ }^{\circ} \mathrm{C}$. Our in situ XPS characterisation data suggests that Taoxides are the catalytically active phase for our CVD conditions, i.e., no reduction to Ta-metal or to Ta-carbide occurs. Such oxide catalysts are particularly promising for CNT growth on reactive substrates such as carbon fibres. ${ }^{20,51}$ Likewise, such reduction-free oxide catalysts may be technologically advantageous for integration of CNTs into electronics since the oxide materials are non-ferromagnetic, show limited reactivity with functional substrates and are already widely used in microelectronics fabrication processes.

\section{Experimental methods}

Metallic Ta thin films were sputter deposited onto Si wafers covered with $\mathrm{SiO}_{2}(200 \mathrm{~nm}), \mathrm{Al}_{2} \mathrm{O}_{3}(10 \mathrm{~nm}$ on top of $200 \mathrm{~nm}$ $\left.\mathrm{SiO}_{2}\right)$, or native oxide $\left(\sim 2 \mathrm{~nm} \mathrm{SiO}_{2}\right)$. Samples were then exposed to ambient air (minimum of $24 \mathrm{~h}$ ) which is known to lead to oxidation of Ta films up to a thickness of $8 \mathrm{~nm} .{ }^{33,52}$ Asformed Ta-oxide films had thicknesses from $0.1 \mathrm{~nm}$ to $5.0 \mathrm{~nm}$ (measured by spectroscopic ellipsometry with an estimated uncertainty in film thickness of $\pm 30 \%$ ). Ta-oxide formation in the films was confirmed by XPS (see below).

Thermal CNT CVD with the Ta-oxide films was performed at atmospheric pressure in a quartz tube furnace with either methane $\left(\mathrm{CH}_{4}\right)$ or acetylene $\left(\mathrm{C}_{2} \mathrm{H}_{2}\right)$ as the carbon precursor. For $\mathrm{CH}_{4}$-based CVD, samples were first heated in $\mathrm{Ar}$ to $850{ }^{\circ} \mathrm{C}-$ $950{ }^{\circ} \mathrm{C}$, then exposed to a $\mathrm{H}_{2}$ pre-treatment step, and subsequently exposed to a $\mathrm{CH}_{4} / \mathrm{H}_{2}$ mixture $(5: 1)$ to achieve CNT growth. For $\mathrm{C}_{2} \mathrm{H}_{2}$-based CVD, samples were first heated in Ar to $650{ }^{\circ} \mathrm{C}-850{ }^{\circ} \mathrm{C}$ and then pre-treated in $\mathrm{H}_{2} / \mathrm{Ar}(5: 2)$, followed by CNT growth in a $\mathrm{C}_{2} \mathrm{H}_{2} / \mathrm{H}_{2} / \mathrm{Ar}$ mixture $(0.1: 5: 2)$. Both CVD recipes have been previously optimised for standard catalysts, ${ }^{34,53}$ and hence allow direct comparison of growth efficiency for the Ta-oxide films. We also note that, despite studying a possibly non-reducing oxide catalyst, it is necessary to keep the $\mathrm{H}_{2}$ in the reaction atmosphere to prevent the formation of an optically visible, silvery amorphous carbon layer that is deposited over the entire inside of the quartz tube and the samples when the $\mathrm{H}_{2}$ flow is fully substituted with an Ar flow (particularly for $\mathrm{C}_{2} \mathrm{H}_{2}$ at $850{ }^{\circ} \mathrm{C}$ ).
The surface chemistry of the samples was analysed using in situ XPS during annealing and hydrocarbon exposure. The former was undertaken via a custom-built X-ray lab-source XPS system while the latter was carried out at the ISISS FHI-MPG beamline at the BESSY II synchrotron, where a differential pumping setup allows XPS measurements on heated samples in atmospheres of up to $\sim 1$ mbar of gas (which is around the maximum attainable pressure in currently available "highpressure" XPS) ${ }^{54}$ Ex-situ XPS (after transfer of samples in air) of Ta-oxide films on all three aforementioned support materials before and after atmospheric pressure CVD showed only signals corresponding to $\mathrm{Ta}, \mathrm{C}, \mathrm{Si}$, O (plus $\mathrm{Al}$ for the $\mathrm{Al}_{2} \mathrm{O}_{3}$-coated substrates), ruling out cross-contamination during processing (XPS wide scans not shown). Morphological characterisation of samples included scanning electron microscopy (SEM), transmission electron microscopy (TEM) and atomic force microscopy (AFM). The quality of the obtained nanotubes was assessed with Raman spectroscopy. For full details of experimental methods see the electronic supplementary information (ESI + ).

\section{Results}

Fig. 1 shows that the Ta-oxide films readily catalyse SWNT and MWNT growth for $\mathrm{CH}_{4}$ - and $\mathrm{C}_{2} \mathrm{H}_{2}$-based CVD, respectively. For both cases the CNT yield depends on the support material, Taoxide thickness and CVD temperature. Bare (i.e., Ta-free) $\mathrm{SiO}_{2}$, $\mathrm{Al}_{2} \mathrm{O}_{3}$ and native oxide substrates all show no CNT growth when exposed to the same CVD conditions. Combined with the lack of traceable contaminants (as evidenced by XPS, see above), this confirms that the CNT growth is indeed catalysed by the presence of the Ta-compound.

For $\mathrm{CH}_{4}$-based CVD the highest CNT yield is obtained on $\mathrm{SiO}_{2}$ support, for which the yield of randomly oriented tubes ( $\sim 40 \mu \mathrm{m}$ length) at $900{ }^{\circ} \mathrm{C}$ and $0.1-0.2 \mathrm{~nm}$ Ta-oxide thickness is comparable to using a standard Fe catalyst ${ }^{53}$ (Fig. 1(a), left). An increase in Ta-oxide film thickness to $0.7-1.0 \mathrm{~nm}$ lowers the CNT yield but gives significantly longer and flow aligned tubes mixed with some short, unaligned tubes (Fig. 1(a), right). The flow aligned CNTs exceed $400 \mu \mathrm{m}$ in length. AFM and TEM analysis (Fig. 2(a,b,c)) shows that the $\mathrm{CH}_{4}$ grown CNTs are single-walled with diameters of $0.6 \mathrm{~nm}$ to $3 \mathrm{~nm}$. For CVD temperatures below $900{ }^{\circ} \mathrm{C}$ or catalyst film thicknesses in excess of $1 \mathrm{~nm}$ no CNT growth is observed for $\mathrm{CH}_{4}$-based CVD.

Changing to $\mathrm{Al}_{2} \mathrm{O}_{3}$ support results in a higher onset temperature for CNT growth of $950{ }^{\circ} \mathrm{C}$, at which short $(\sim 5$ $\mu \mathrm{m})$ and sparse CNTs are found for Ta-oxide film thicknesses ranging from 0.2 to $1.0 \mathrm{~nm}$ (see Supplementary Fig. 1 in the ESI). Native oxide covered Si wafers as support show no CNT growth for any of the conditions tested.

For $\mathrm{C}_{2} \mathrm{H}_{2}$-based $\mathrm{CVD}$ at comparatively lower temperatures $\left(650{ }^{\circ} \mathrm{C}-750{ }^{\circ} \mathrm{C}\right)$ entangled bundles of short, curled tubes are observed for $\mathrm{SiO}_{2}$ supported Ta-oxide films with thicknesses ranging from 0.2 to $0.7 \mathrm{~nm}$. At a growth temperature of $850{ }^{\circ} \mathrm{C}$ the CNTs nucleate from 0.2 to $2.0 \mathrm{~nm}$ thick Ta-oxide films, 

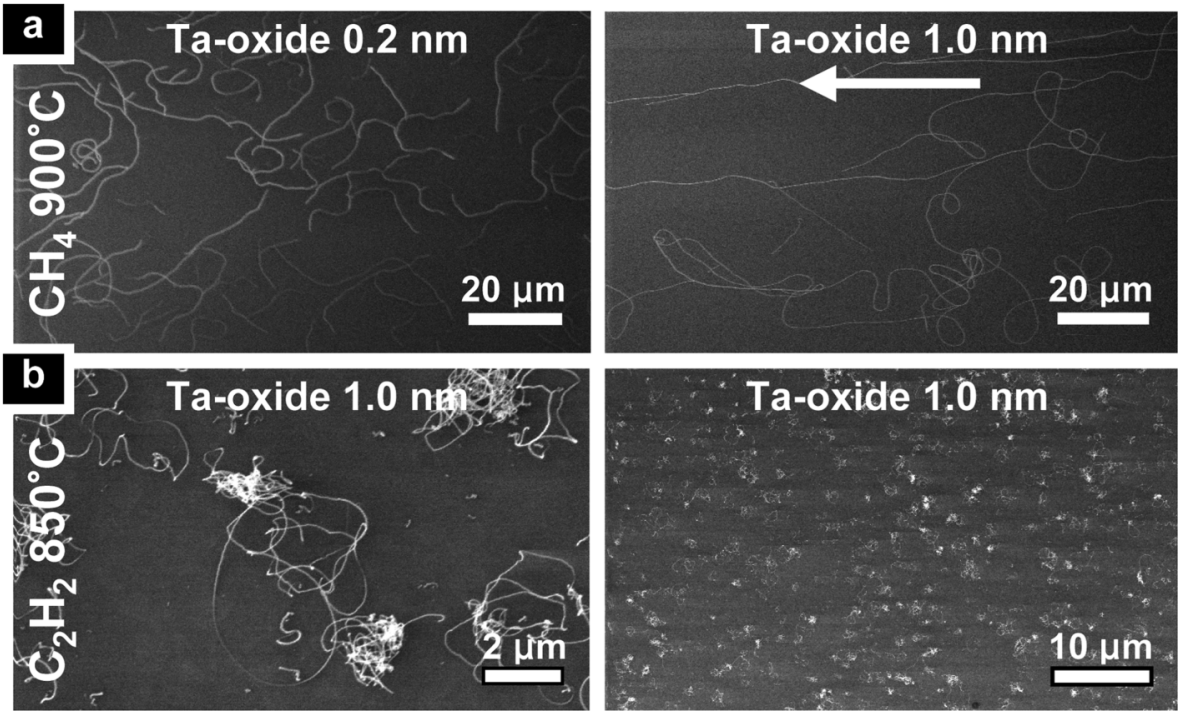

Fig. $1 \mathrm{SEM}$ images of typical growth results from (a) $\mathrm{CH}_{4}$-based and (b) $\mathrm{C}_{2} \mathrm{H}_{2}$-based $\mathrm{CVD}$ on $\mathrm{SiO}_{2}$ with varying CVD temperature and Ta-oxide thickness, as indicated in the figure. The arrow indicates process gas flow direction. Growth results are homogeneous across macroscopic samples.

with an optimum yield for $1.0 \mathrm{~nm}$ thick Ta-oxide (Fig. 1(b)). For Ta-oxide films thicker than $2 \mathrm{~nm}$ no CNTs are observed. This appears consistent with recent literature, which reports no observable CNT growth from ambient air exposed $3 \mathrm{~nm}$ Ta films under similar CVD conditions. ${ }^{46}$ Fig. 2 (d) shows that Ta- oxide catalysed nanotubes are multi-walled for the $\mathrm{C}_{2} \mathrm{H}_{2}$-based CVD recipes with diameters of $10-25 \mathrm{~nm}$. The multi-walled nature of the nanotubes is corroborated by the Raman analysis in Fig. $2(\mathrm{e}) .^{34}$ For typical $750{ }^{\circ} \mathrm{C}$ grown tubes we find in Fig. $2(\mathrm{e})$ a D/G intensity ratio of $\sim 0.9$ which is the same as for $\mathrm{Fe}$
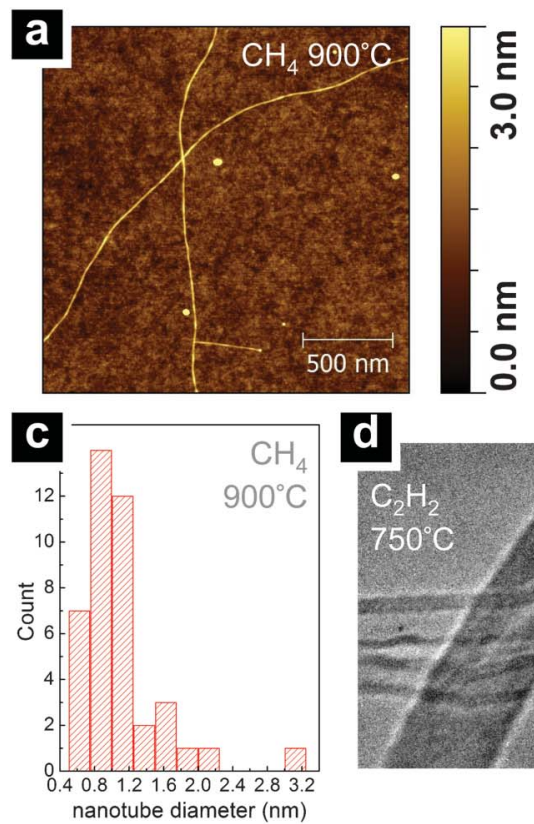
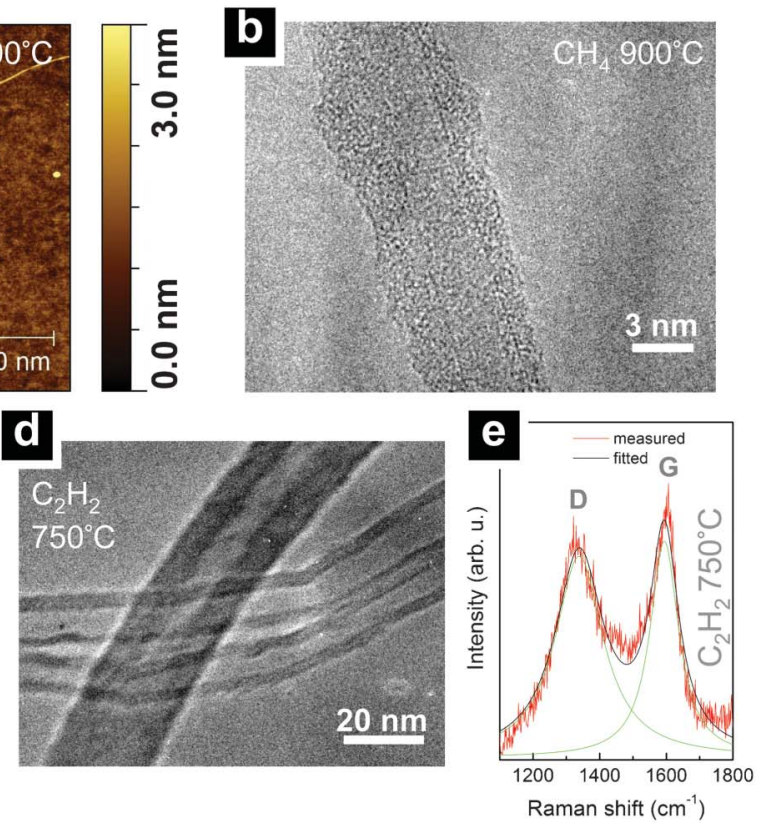

Fig. 2 (a) Typical AFM scan of $\mathrm{CH}_{4}$ grown nanotubes $\left(900{ }^{\circ} \mathrm{C}\right.$ with $0.2 \mathrm{~nm}$ thick Ta-oxide on $\mathrm{SiO}_{2}$ ). (b) TEM image of a $\mathrm{CH}_{4}$ grown SWNT (900 ${ }^{\circ} \mathrm{C}$ with $0.2 \mathrm{~nm}$ Ta-oxide grown on $\mathrm{SiO}_{2}$ TEM membrane). Note that the SWNT is coated with amorphous carbon from TEM characterisation. (c) Histogram of AFM- and TEM-extracted diameters for $\mathrm{CH}_{4}$ grown nanotubes from $0.2 \mathrm{~nm}$ thick Ta-oxide on $\mathrm{SiO}_{2}$. The observed diameter range clearly indicates SWNT formation. (d) TEM image of $\mathrm{C}_{2} \mathrm{H}_{2}$ grown nanotubes $\left(750^{\circ} \mathrm{C}\right.$ with $0.5 \mathrm{~nm}$ Ta-oxide on $\mathrm{SiO}_{2}$, scratched off onto the TEM grid). The diameter range and the hollow cores indicate MWNT formation. (e) Raman spectrum $(633 \mathrm{~nm})$ of $\mathrm{C}_{2} \mathrm{H}_{2}$ grown nanotubes $\left(750^{\circ} \mathrm{C}\right.$ with $0.7 \mathrm{~nm}$ Ta-oxide on $\left.\mathrm{SiO}_{2}\right)$. The $\mathrm{G}$ and $\mathrm{D}$ features in the Raman spectrum are consistent with MWNT formation. ${ }^{34}$ Fitting the $G$ and $D$ Raman features with Lorentzians, a D/G ratio of $\sim 0.9$ is obtained, comparable to $D / G$ ratios for standard Fe catalysts under the same $\mathrm{C}_{2} \mathrm{H}_{2} 750{ }^{\circ} \mathrm{C} \mathrm{CVD}$ conditions. ${ }^{34}$ 
catalyst reference samples grown under the same CVD conditions. ${ }^{34}$ This confirms that the Ta-oxide films on $\mathrm{SiO}_{2}$ facilitate growth of nanotubes of reasonable quality.

The same Ta-oxide films on $\mathrm{Al}_{2} \mathrm{O}_{3}$ support with $\mathrm{C}_{2} \mathrm{H}_{2}$ show a higher growth onset temperature of $\sim 850{ }^{\circ} \mathrm{C}$, at which only sparse, uncontrolled growth of entangled CNT bundles is observed for 0.7 to $1.0 \mathrm{~nm}$ Ta. Consistent with the $\mathrm{CH}_{4}$ results, for Si wafers covered only with a native oxide as support no CNT growth is observed for any of the conditions sampled for $\mathrm{C}_{2} \mathrm{H}_{2}$.

In order to rationalise this growth behaviour, we systematically analyse the state of the Ta in the catalyst films during the CVD process by in situ XPS. Fig. 3 compares the changes in Ta4f core level signatures upon vacuum annealing of $0.2 \mathrm{~nm}$ Ta-oxide supported on $\mathrm{SiO}_{2}\left(200 \mathrm{~nm} \mathrm{SiO}_{2}\right.$ on Si-wafer) and native oxide covered $\left.\mathrm{Si}(\sim 2 \mathrm{~nm} \mathrm{SiO})_{2}\right)$. In the text we refer the binding energies of the various Ta chemical states to the $\mathrm{Ta}_{4 / 2}$ peak which is labelled with the respective state assignments in all XPS figures. The second peak feature at higher binding energy (with a constant offset of $\sim 1.9 \mathrm{eV}$ to the $\mathrm{Ta}_{4 / 2}$ ) is the corresponding $\mathrm{Ta}_{4} \mathrm{f}_{5 / 2}$ for the same chemical state.

In their as-deposited state (after air exposure), the films show only peaks corresponding to Ta-oxides $\left(\mathrm{Ta}_{4} \mathrm{f}_{7 / 2}\right.$ at $26.2 \pm$ $0.2 \mathrm{eV}) .^{43,52,55-57}$ As expected for very thin Ta films after ambient air exposure, ${ }^{33,52}$ oxidation of the entire films is

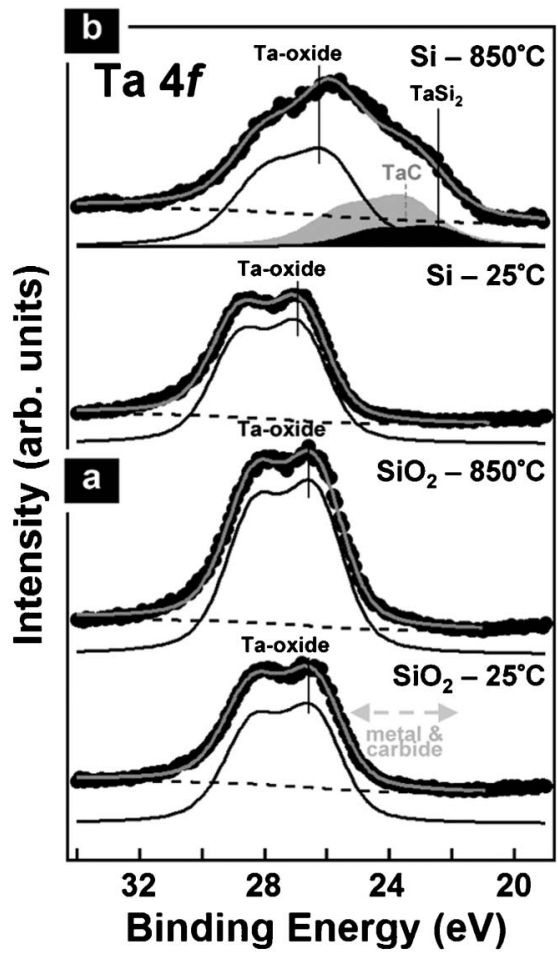

Fig. 3 In situ XPS of $0.2 \mathrm{~nm}$ Ta-oxide films on (a) $\mathrm{SiO}_{2}$ and (b) $\mathrm{Si}$ at room temperature (as deposited) and during annealing at $850{ }^{\circ} \mathrm{C}$ in $\sim 10^{-8} \mathrm{mbar}$ vacuum (5 min). While on $\mathrm{SiO}_{2}$ the Ta-oxide remains oxidised during annealing, on Si partial Ta-silicidation occurs. (We additionally observe Ta-carbide formation on $\mathrm{Si}$, which we ascribe to interaction with adventitious carbon from transport in air.) confirmed and no peaks corresponding to Ta-metal $\left(\mathrm{Ta} 4 \mathrm{f}_{7 / 2}\right.$ $\sim 22 \mathrm{eV}$ ) or Ta-carbide $\left(\mathrm{Ta}_{4} \mathrm{f}_{7 / 2} \sim 23.3 \mathrm{eV}\right.$ ) are found. ${ }^{43,52,55-57}$

When heated in vacuum, the thin Ta-oxide on $\mathrm{SiO}_{2}$ support does not change its chemical state, i.e., it stays oxidised even at $850{ }^{\circ} \mathrm{C}$ (Fig. 3(a)). This is in dramatic contrast to the behaviour seen for surface Ta-oxide on thicker Ta films $(\sim 100 \mathrm{~nm}$ on $\mathrm{SiO}_{2}$ ), where we found that the surface oxide readily reduces under similar annealing conditions. ${ }^{34}$ This suggests that the thin Ta-oxide is interfacially stabilised by the close proximity to the $\mathrm{SiO}_{2}$ support.

On the contrary, Fig. 3(b) shows that on the $\sim 2 \mathrm{~nm}$ native oxide support a partial silicidation, i.e. formation of $\mathrm{TaSi}_{2}$, occurs during the high temperature annealing $\left(\mathrm{Ta}_{4} \mathrm{f}_{7 / 2}\right.$ at $\sim 22.6 \mathrm{eV}){ }^{58-60}$ Additionally we observe Ta-carbide formation $\left(\mathrm{Ta}_{4} \mathrm{f}_{7 / 2} \sim 23.5 \mathrm{eV}\right)$, most likely due to the interaction with adventitious carbon from the sample transfer in air and facilitated by the silicidation reaction. This silicon-mediated Ta-oxide reduction and Ta-silicidation clearly explains why no CNT growth is observed for the native oxide support. The approximately $2 \mathrm{~nm}$ thick native oxide is not sufficiently thick to isolate the Ta atoms from the bulk Si. The resulting silicide formation leads to deactivation of the catalyst similar as in the case of standard catalysts. ${ }^{61}$ It is however important to note that the as-formed Ta silicide gets re-oxidised upon air exposure over the duration of several days. This can obscure the actual differences between the thick $\mathrm{SiO}_{2}$ and native oxide support for ex-situ XPS and hence this clearly highlights the motivation for our in situ measurements.

Fig. 4 shows process-step resolved Ta4f core level signatures recorded by synchrotron-based in situ XPS during low pressure $\mathrm{H}_{2}$ and $\mathrm{C}_{2} \mathrm{H}_{2}$ exposures $\left(0.5\right.$ mbar) of a $\mathrm{SiO}_{2}(200 \mathrm{~nm})$ supported $0.5 \mathrm{~nm}$ thick Ta-oxide film at $\sim 750{ }^{\circ} \mathrm{C}$.

Compared to the lab-source-based XPS scans in Fig. 3 and Fig. 5, the synchrotron-based XPS has a higher resolution, allowing us to resolve the contributions of particular oxidation states in the Ta-oxide. In Fig. 4, the XPS signature of the asloaded Ta film is dominated by contributions of $\mathrm{Ta}^{4+}\left(\mathrm{Ta}_{4 / 2}\right.$ $\sim 26.7 \mathrm{eV})$ and $\mathrm{Ta}^{5+}\left(\mathrm{Ta}_{7 / 2} \sim 27.2 \mathrm{eV}\right)$ oxidation states. This signature does not significantly change during annealing in $\sim 0.5 \mathrm{mbar}_{2}$, neither for the subsequent addition of $\mathrm{C}_{2} \mathrm{H}_{2}$, nor for the final CVD atmosphere of $\sim 0.5$ mbar of undiluted $\mathrm{C}_{2} \mathrm{H}_{2}$. Again we find that these $\mathrm{SiO}_{2}$ supported thin Ta-oxide films are much less reactive than surface Ta-oxides on thicker metallic Ta films $\left(\sim 100 \mathrm{~nm}\right.$ Ta on $\left.\mathrm{SiO}_{2}\right)$ that were readily transformed to a carbide under such $\mathrm{C}_{2} \mathrm{H}_{2}$ exposure conditions. ${ }^{34}$ This again suggests interfacial stabilisation of the thin Ta-oxide by the $\mathrm{SiO}_{2}$ support where the Ta-oxide is preserved even in strongly reducing environments.

We note that due to the pressure limitations of the in situ XPS set-up ${ }^{54}$ the Ta phase during the atmospheric CNT CVD conditions cannot be directly probed. We hence carried out a range of complementary ex-situ XPS measurements. Fig. 5 shows such ex-situ XPS scans after atmospheric $\mathrm{CH}_{4}$-based $\mathrm{CVD}$ at $900{ }^{\circ} \mathrm{C}$ for $0.2 \mathrm{~nm}$ thick Ta-oxide supported on $\mathrm{SiO}_{2}$ and $\mathrm{Al}_{2} \mathrm{O}_{3}$. Consistent with the in situ XPS, the post-growth signature of $\mathrm{SiO}_{2}$ supported thin Ta-oxide only shows peaks 


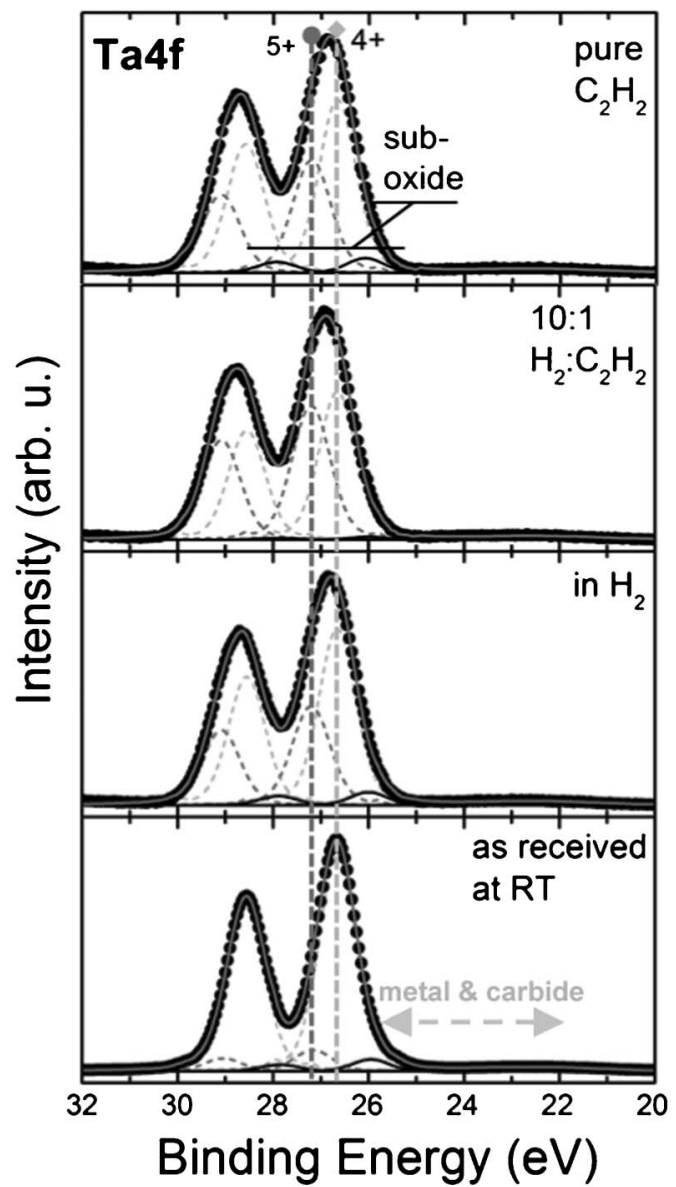

Fig. 4 Process-step resolved in situ XPS of a $0.5 \mathrm{~nm}$ Ta-oxide film on $\mathrm{SiO}_{2}$ during low pressure CVD at $\sim 750{ }^{\circ} \mathrm{C}$ in a total pressure of $\sim 0.5 \mathrm{mbar}$. From bottom to top: As loaded catalyst film at room temperature, at $750{ }^{\circ} \mathrm{C}$ in $0.5 \mathrm{mbar} \mathrm{H}_{2}$, at $750{ }^{\circ} \mathrm{C}$ in $0.5 \mathrm{mbar}_{2} / \mathrm{C}_{2} \mathrm{H}_{2}(10: 1)$ and at $750{ }^{\circ} \mathrm{C}$ in 0.5 mbar $\mathrm{C}_{2} \mathrm{H}_{2}$. Notably, the Ta remains in an oxidised state during the process $\left(\mathrm{Ta}^{4+}\right.$ and $\left.\mathrm{Ta}^{5+}\right)$, never showing carbidic or metallic components.

corresponding to Ta-oxides $\left(\mathrm{Ta}_{4} \mathrm{f}_{7 / 2}\right.$ at $\sim 26.2 \mathrm{eV}$ ), while no peaks corresponding to Ta-metal $\left(\mathrm{Ta}_{4} \mathrm{f}_{7 / 2} \sim 22 \mathrm{eV}\right)$ and -carbide $\left(\mathrm{Ta}_{4} \mathrm{f}_{7 / 2} \sim 23.3 \mathrm{eV}\right)$ are found. ${ }^{43,52,55-57}$ The post growth C1s signature shows $\mathrm{sp}^{2}$-bound carbon $(\mathrm{C} 1 \mathrm{~s} \sim 284.5 \mathrm{eV})$, in agreement with the SEM observations of grown nanotubes (Fig. 1(a), left). Interestingly, the $\mathrm{Al}_{2} \mathrm{O}_{3}$ supported Ta-oxide films show additional peaks at $23.1 \pm 0.2 \mathrm{eV}$ in the Ta4f energy region and at $282.7 \pm 0.2 \mathrm{eV}$ in the $\mathrm{C} 1 \mathrm{~s}$ energy region after CVD processing with $\mathrm{CH}_{4}$ at $900{ }^{\circ} \mathrm{C}$ (Fig. 5). The additional peaks can be attributed to Ta-carbide (where the $\sim 284.5 \mathrm{eV}$ signal in the $\mathrm{C} 1 \mathrm{~s}$ region is attributed to graphitic fragments as no nanotube were grown at $900{ }^{\circ} \mathrm{C}$ on $\left.\mathrm{Al}_{2} \mathrm{O}_{3}\right) \cdot{ }^{43,52,55-57}$ The admixture of $\mathrm{Al} / \mathrm{Al}_{2} \mathrm{O}_{3}$ to Ta-oxides is known to change the oxides' structural evolution with temperature $^{62,63}$ and may lower the temperature for partial Ta-oxide reduction. ${ }^{64}$ This could relate to the observed carbide formation here. This carbide formation may in turn relate to the lower CNT growth yield and higher growth onset temperatures we observed for $\mathrm{Al}_{2} \mathrm{O}_{3}$ supported Ta-oxide films.

\section{Discussion}

In a previous study regarding Ta-containing bimetallic FeTa co-catalysts for CNT growth, ${ }^{47}$ we exposed similarly thin, ambient air exposed Ta films to low pressure CVD but did not find CNT growth. This is in contrast to the successful atmospheric pressure CNT CVD presented here, which suggests that Ta-based catalysts need a high partial pressure of the carbon source, similar to most non-standard catalysts. Furthermore, the growth data in the present study also highlights the importance of a low initial Ta-oxide film thickness for CNT nucleation.

Previous reduction studies on Ta-oxides found that Taoxide reduction by $\mathrm{H}_{2}{ }^{64,65}$ as well as carbothermal reduction ${ }^{66}$ require temperatures in excess of $1050{ }^{\circ} \mathrm{C}$, significantly above our CVD conditions. In a previous study we have also established the presence of significant amounts of residual oxygen/water in our atmospheric CVD system even in nominally reducing gas mixtures. ${ }^{34}$ Considerations of the Ta-C-O phase diagram at $600-750{ }^{\circ} \mathrm{C}$ have suggested that Taoxide is stable over TaC when a small oxygen partial pressure is present. ${ }^{67}$ This leads us to hypothesise that, as with $\mathrm{ZrO}_{2}{ }^{20}$ the Ta-based catalyst during nanotube growth is actually in its oxide form for our CVD conditions. This is in agreement with the key observation that for the thin Ta-oxide films on $\mathrm{SiO}_{2}$, the substrate that allowed SWNT and MWNT growth with the highest yield, all our in situ and ex-situ XPS measurements showed no carbidic or metallic Ta-components but only Taoxide.

Additionally, when phases other than Ta-oxides were detected by XPS in the films the CNT growth yield was greatly reduced. On the Si support we found that the formation of Tasilicides hindered CNT growth completely and on the $\mathrm{Al}_{2} \mathrm{O}_{3}$ support we found that the presence of Ta-carbide (in addition to the oxide) correlates with a greatly reduced CNT growth window. Combination of these observations corroborates an interpretation of our data towards Ta being an active CNT catalyst in its oxide form under our CVD conditions.

\section{Conclusions}

We find that technologically important, ULSI-process compatible Ta-oxide thin films catalyse SWNT growth with $\mathrm{CH}_{4}$ and MWNT growth with $\mathrm{C}_{2} \mathrm{H}_{2}$ (at moderate temperatures as low as $650{ }^{\circ} \mathrm{C}$ ). This is important as most non-standard catalysts only catalyse high temperature SWNT growth. A low film thickness, the nature of the support material (where best results were observed with $\mathrm{SiO}_{2}$ ), and atmospheric process gas pressure are of key importance for successful nanotube nucleation. Strong material interactions, such as silicide formation on Si, inhibit CNT growth. Our ex- and in situ characterisation data suggests that no catalyst reduction to Ta-metal or Ta-carbide occurs during our CVD conditions and that the catalytically active phase is the Ta-oxide phase. 

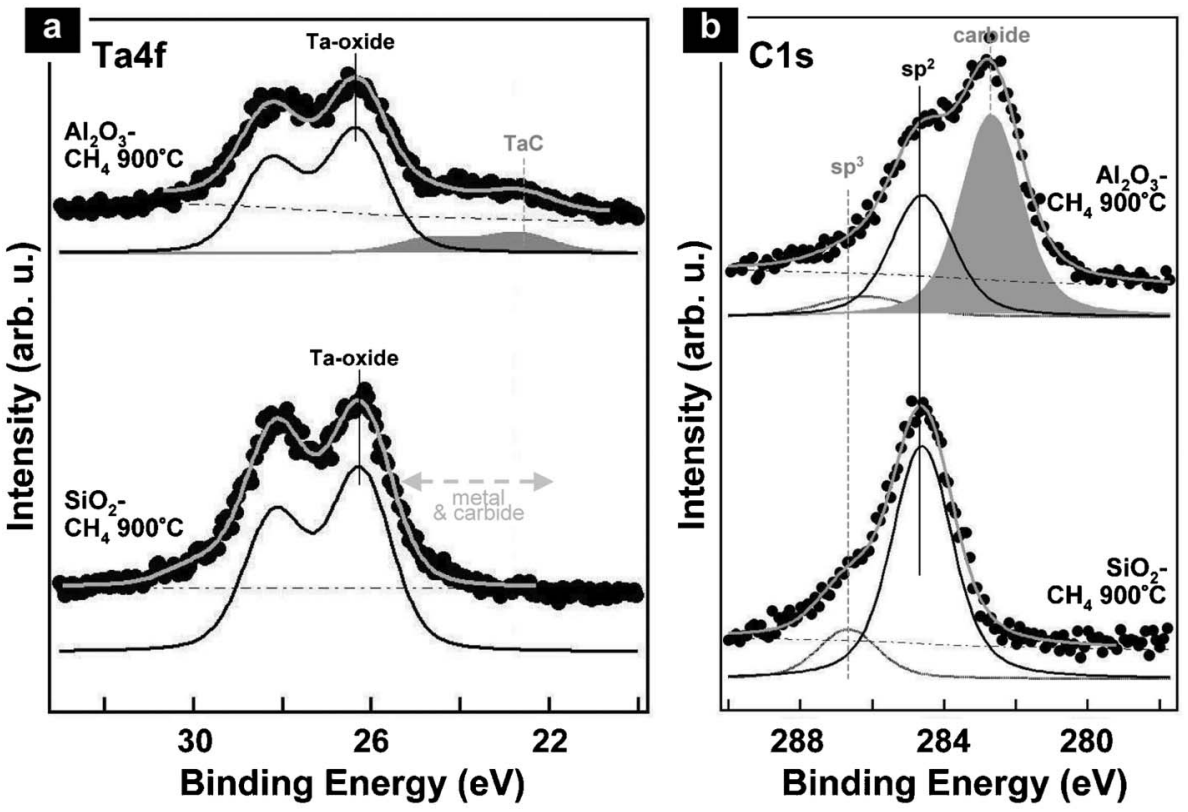

Fig. 5 Ex-situ (a) Ta4f and (b) C1s XPS scans of $0.2 \mathrm{~nm}$ Ta-oxide films after $\mathrm{CH}_{4}$-based $\mathrm{CVD}$ at $900{ }^{\circ} \mathrm{C}$ on (from bottom to top) $\mathrm{SiO}_{2}$ (CNT growth) and $\mathrm{Al}_{2} \mathrm{O}_{3}$ (no growth). On $\mathrm{SiO}_{2}$, the Ta4f spectrum shows only signals corresponding to Ta-oxide. On $\mathrm{Al}_{2} \mathrm{O}_{3}$, the dominant feature is also Ta-oxide but a Ta-carbide contribution is additionally found (matched by a corresponding carbide signature in (b)).

\section{Acknowledgements}

S.H. acknowledges funding from the EPSRC (Grant No. EP/ H047565/1) and from ERC grant InsituNANO (project reference 279342). We acknowledge the Helmholtz-Zentrum-Berlin BESSY II synchrotron, and we thank the BESSY staff for continuous support. We acknowledge partial funding from the EC project Technotubes. C.D. acknowledges the Royal Society for funding and B.C.B. acknowledges a Research Fellowship from Hughes Hall, Cambridge.

\section{References}

1 S. Hofmann, R. Sharma, C. Ducati, G. Du, C. Mattevi, C. Cepek, M. Cantoro, S. Pisana, A. Parvez, F. CervantesSodi, A. C. Ferrari, R. Dunin-Borkowski, S. Lizzit, L. Petaccia, A. Goldoni and J. Robertson, Nano Lett., 2007, 7, 602.

2 J.-P. Tessonnier and D. S. Su, ChemSusChem, 2011, 4, 824.

3 M. Fouquet, B. C. Bayer, S. Esconjauregui, R. Blume, J.

H. Warner, S. Hofmann, R. Schlögl, C. Thomsen and J. Robertson, Phys. Rev. B: Condens. Matter Mater. Phys., 2012, 85, 235411.

4 C. T. Wirth, B. C. Bayer, A. D. Gamalski, S. Esconjauregui, R. S Weatherup, C. Ducati, C. Baehtz, J. Robertson and S. Hofmann, Chem. Mater., 2012, 24, 4633.

5 W. Zhou, Z. Han, J. Wang, Y. Zhang, J. Zhong, X. Sun, Y. Zhang, C. Yan and Y. Li, Nano Lett., 2006, 6, 2987.

6 D. Takagi, Y. Homma, H. Hibino, S. Suzuki and Y. Kobayashi, Nano Lett., 2006, 6, 2642.

7 D. Yuan, L. Ding, H. Chu, Y. Feng, T. P. McNicholas and J. Liu, Nano Lett., 2008, 8, 2576.
8 S. Bhaviripudi, E. Mile, S. A. Steiner III, A. T. Zare, M. S. Dresselhaus, A. M. Belcher and J. Kong, J. Am. Chem. Soc., 2007, 129, 1516.

9 S. Esconjauregui, C. M. Whelan and K. Maex, Carbon, 2009, 47, 659.

10 T. Uchino, K. N. Bourdakos, C. H. de Groot, P. Ashburn, M. E. Kiziroglou, G. D. Dilliway and D. C. Smith, Appl. Phys. Lett., 2005, 86, 233110.

11 D. Takagi, H. Hibino, S. Suzuki, Y. Kobayashi and Y. Homma, Nano Lett., 2007, 7, 2272.

12 D. Takagi, Y. Kobayashi and Y. Homma, J. Am. Chem. Soc., 2009, 131, 6922.

13 X. Yu, J. Zhang, W. Choi, J.-Y. Choi, J. M. Kim, L. Gan and Z. Liu, Nano Lett., 2010, 10, 3343.

14 J. H. Lin, C. S. Chen, M. H. Ruemmeli, A. Bachmatiuk, Z. Y. Zeng, H. L. Ma, B. Buechner and H. W. Chen, Chem. Mater., 2011, 23, 1637.

15 H. Liu, D. Takagi, H. Ohno, S. Chiashi, T. Chokan and Y. Homma, Appl. Phys. Express, 2008, 1, 014001.

16 E. J. Bae, W. B. Choi, K. S. Jeong, J. U. Chu, G.-S. Park, S. Song and I. K. Yoo, Adv. Mater., 2002, 14, 277.

17 J. J. Schneider, N. I. Maksimova, J. Engstler, R. Joshi, R. Schierholz and R. Feile, Inorg. Chim. Acta, 2008, 361, 1770.

18 B. Liu, W. Ren, L. Gao, S. Li, S. Pei, C. Liu, C. Jiang and H. Cheng, J. Am. Chem. Soc., 2009, 131, 2082.

19 S. Huang, Q. Cai, J. Chen, Y. Qian and L. Zhang, J. Am. Chem. Soc., 2009, 131, 2094.

20 S. A. Steiner III, T. F. Baumann, B. C. Bayer, R. Blume, M. A. Worsley, W. J. MoberlyChan, E. L. Shaw, R. Schlögl, A. J. Hart, S. Hofmann and B. L. Wardle, J. Am. Chem. Soc., 2009, 131, 12144. 
21 B. Liu, D.-M. Tang, C. Sun, C. Liu, W. Ren, F. Li, W.-J. Yu, L.-C. Yin, L. Zhang, C. Jiang and H.-M. Cheng, J. Am. Chem. Soc., 2011, 133, 197.

22 H. Liu, D. Takagi, S. Chiashi and Y. Homma, Carbon, 2010, 48, 114.

23 A. Bachmatiuk, F. Boerrnert, M. Grobosch, F. Schaeffel, U. Wolff, A. Scott, M. Zaka, J. H. Warner, R. Klingeler, M. Knupfer, B. Buechner and M. H. Ruemmeli, ACS Nano, 2009, 3, 4098.

24 A. J. Page, K. R. S. Chandrakumar, S. Irle and K. Morokuma, J. Am. Chem. Soc., 2011, 133, 621.

25 F. Gao, L. Zhang and S. Huang, Appl. Surf. Sci., 2010, 256, 2323.

26 Q. Cai, Y. Hu, Y. Liu and S. Huang, Appl. Surf. Sci., 2012, 258, 8019.

27 M. H. Rummeli, A. Bachmatiuk, A. Scott, F. Borrnert, J. H. Warner, V. Hoffman, J.-H. Lin, G. Cuniberti and B. Buchner, ACS Nano, 2010, 4, 4206.

28 P. R. Kidambi, B. C. Bayer, R. S. Weatherup, R. Ochs, C. Ducati, D. V. Szabó and S. Hofmann, Phys. Status Solidi $R R L, 2011,5,341$.

29 J. Robertson, J. Mater. Chem., 2012, 22, 19858.

30 C. P. Deck and K. Vecchio, Carbon, 2006, 44, 267.

31 Y. Homma, H. Liu, D. Takagi and Y. Kobayashi, Nano Res., 2009, 2, 793.

32 Binary Alloy Phase Diagrams, ed. T. B. Massalski, ASM International, USA, 2nd edn, 1990.

33 S. M. Cardonne, P. Kumar, C. A. Michaluk and H. D. Schwartz, Int. J. Refract. Met. Hard Mater., 1995, 13, 187.

34 B. C. Bayer, S. Hofmann, C. Castellarin-Cudia, R. Blume, C. Baehtz, S. Esconjauregui, C. T. Wirth, R. A. Oliver, C. Ducati, A. Knop-Gericke, R. Schlögl, A. Goldoni, C. Cepek and J. Robertson, J. Phys. Chem. C, 2011, 115, 4359.

35 S. M. Irving and P. L. Walker, Carbon, 1967, 5, 399.

36 S. A. Steiner III, Master's Thesis, Massachusetts Institute of Technology, 2006.

37 M. Terrones, W. K. Hsu, H. Terrones, J. P. Zhang, S. Ramos, J. P. Hare, R. Castillo, K. Prassides, A. K. Cheetham, H. W. Kroto and D. R. M. Walton, Chem. Phys. Lett., 1996, 259, 568.

38 H. Li, C. Xue, H. Zhuang, J. Chen, Z. Yang, L. Qin, Y. Huang and D. Zhang, Mater. Chem. Phys., 2008, 109, 249.

39 P. Nguyen, H. T. Ng and M. Meyyappan, Adv. Mater., 2005, 17, 1773.

40 T. Tanaka, H. Nojima, T. Yamamoto, S. Takenaka, T. Funabik and S. Yoshida, Phys. Chem. Chem. Phys., 1999, 1, 5235.

41 T. Usjikubo, Catal. Today, 2000, 57, 331.

42 Y. Chen, J. L. G. Fierro, T. Tanaka and I. E. Wachs, J. Phys. Chem. B, 2003, 107, 5243.

43 J. Choi, Appl. Catal., A, 1999, 184, 189.

44 I. Kojima, E. Miyazaki, Y. Inoue and I. Yasumori, J. Catal., 1982, 73, 128.
45 J.-G. Choi, H.-G. Oh and Y.-S. Baek, J. Ind. Eng. Chem., 1998, 4, 94 .

46 G. D. Nessim, M. Seita, K. P. O’Brien and S. A. Speakman, Carbon, 2010, 48, 4519.

47 B. C. Bayer, M. Fouquet, R. Blume, C. T. Wirth, R. S. Weatherup, K. Ogata, A. Knop-Gericke, R. Schlögl, S. Hofmann and J. Robertson, J. Phys. Chem. C, 2012, 116, 1107.

48 CRC Handbook of Chemistry and Physics, ed. R. C. Weast, CRC press, Cleveland, Ohio, USA, 56th edn, 1975.

49 R. Steinitz and R. Resnick, J. Appl. Phys., 1966, 37, 3463.

50 C. Chaneliere, J. L. Autran, R. A. B. Devine and B. Balland, Mater. Sci. Eng., R, 1998, 22, 269.

51 H. Qian, E. S. Greenhalgh, M. S. P. Shaffer and A. Bismarck, J. Mater. Chem., 2010, 20, 4729.

52 M. Khanuja, H. Sharma, B. R. Mehta and S. M. Shivaprasad, J. Electron Spectrosc. Relat. Phenom., 2009, 169, 41.

53 S. Pisana, A. Jungen, C. Zhang, A. M. Blackburn, R. Sharma, F. Cervantes-Sodi, C. Stampfer, C. Ducati, A. C. Ferrari, C. Hierold, J. Robertson and S. Hofmann, J. Phys. Chem. C, 2007, 111, 17249.

54 A. Knop-Gericke, E. Kleimenov, M. Hävecker, R. Blume, D. Teschner, S. Zafeiratos, R. Schlögl, V. I. Bukhtiyarov, V. V. Kaichev, I. P. Prosvirin, A. I. Nizovskii, H. Bluhm, A. Barinov, P. Dudin and M. Kiskinova, Adv. Catal., 2009, 52, 213.

55 D. Yang, H. Jiang, R. Ott, K. Minor, J. Grant, L. Varga, J. A. Barnard and W. D. Doyle, Surf. Interface Anal., 1999, 27, 259.

56 E. Atanassova, G. Tyuliev, A. Paskaleva, D. Spassov and K. Kostov, Appl. Surf. Sci., 2004, 225, 86.

57 B. S. Itchkawitz, P. F. Lyman, G. W. Ownby and D. M. Zehner, Surf. Sci., 1994, 318, 395.

58 A. Y. Mao, K. A. Son, J. M. White, D. L. Kwong, D. A. Roberts and R. N. Vrtis, J. Vac. Sci. Technol., A, 1999, 17, 954.

59 S. Kohli, P. R. McCurdy, C. D. Rithner, P. K. Dorhout, A. M. Dummer, F. Brizuela and C. S. Menoni, Thin Solid Films, 2004, 469-470, 404.

60 X. Zhao, N. P. Magtoto, M. Leavy and J. A. Kelber, Thin Solid Films, 2002, 415, 308.

61 J. M. Simmons, B. M. Nichols, M. S. Marcus, O. M. Castellini, R. J. Hamers and M. A. Eriksson, Small, 2006, 2, 902.

62 S. Wu, H. M. Chan and M. P. Harmer, J. Am. Ceram. Soc., 2005, 88, 2369.

63 M. K. Hota, C. Mahata, M. K. Bera, S. Mallik, C. K. Sarkar, S. Varma and C. K. Maiti, Thin Solid Films, 2010, 519, 423.

64 J. P. Kim, Korean J. Chem. Eng., 2004, 21, 385.

65 I. E. Wachs, Y. Chen, J. Jehng, L. E. Briand and T. Tanaka, Catal. Today, 2003, 78, 13.

66 D. Kwon, S. Hong and B. Kim, Mater. Lett., 2004, 58, 3863.

67 T. Laurila, K. Zeng, J. K. Kivilahti, J. Molarius and I. Suni, Appl. Phys. Lett., 2002, 80, 938. 